Note: this is a preprint of a paper of mine that is forthcoming in History and Philosophy of Logic. It is not at all meant to replace the origin. This preprint mustn't be quoted, only quote from the final version.

\title{
J.S. Mill's Canons of Induction: from True Causes to Provisional Ones
}

\section{STEFFEN DUCHEYNE}

Centre for Logic and Philosophy of Science, Ghent University, Blandijnberg 2, B-9000 Ghent, Belgium, email: Steffen.Ducheyne@UGent.be

Deduction is a game and induction a grievance. (Bagehot 1913, vol. 3, p. 37)

In this essay, my aim is twofold: to clarify how the late Mill conceived of the certainty of inductive generalizations and to offer a systematic clarification of the limited domain of application of the Mill's Canons of Induction. I shall argue that Mill's views on the certainty of knowledge changed overtime and that this change was accompanied by a new view on the certainty of the inductive results yielded by the Canons of Induction. The key message of the later editions of The System of Logic as conceived by the late Mill was no longer that by the Canons of Induction we can establish scientific certainty and true causes, but rather that the Canons are useful in establishing causal laws in a provisional way.

\section{Introduction}

In this essay, I establish two things: I (1) clarify how the late Mill conceived of the certainty of inductive generalizations and (2) offer a systematic clarification of the limited domain of application of the Canons of Induction.

I shall argue that Mill's views on the certainty of knowledge changed overtime and that this change was accompanied by a new view on the certainty of the inductive results yielded by the 
Canons of Induction. In addition, I offer a systematic unravelling of the underlying presuppositions of Mill's Canons of Induction and, in view of this, clarify the limited scope of Mill's Canons. Nowhere do I assume that Mill's A System of Logic provides an adequate theoretical account of induction and causation. One obvious objection is that Mill treats induction as intrinsically causal (and only considers deterministic causation). Also several of the presuppositions of Mill's Canons do not apply to all forms of causation (see infra). Undoubtedly, Mill's Canons remain heuristically valuable if we already have an idea of the possible causes relevant to an explanandum. ${ }^{1}$

Past interpreters of Mill have concluded that Mill thought that applications of the Canons establish causal laws beyond doubt. Alan Ryan for instance notes that Mill thought that experimental methods 'are designed to prove natural laws to be true' (1971, p. 41), that Mill 'has an almost Aristotelian tendency to identify generality and certainty', that 'he never ceases to stress the need to arrive at certain natural laws' $(1974$, p. 80), and that the Canons of Induction are 'supposed to show how we prove a hypothesis to be true' (ibid.). R.P. Anschutz noted that Mill attempted to formulate a demonstrative theory of induction, which would produce 'a perfect science both of natural bodies and of spiritual' (1963 [1953], p. 111 [emphasis in original]). While these statements apply to the early Mill, they do not to the late Mill.

${ }^{1}$ Cf. Nagel 1950, p. xli. Nagel adds that although they require further factual assumptions, they nevertheless succeed in calling attention 'to considerations that are indispensable in evaluating much empirical evidence'. Cf. Mackie's conclusion: 'In fact, these methods are constantly used, explicitly of implicitly, both to suggest causal hypotheses and to confirm them. One should not, of course, expect any methods of empirical enquiry to establish conclusions beyond all possibility of doubt or all need of refinement, but using these methods we can frequently say at least this: we have reason to suppose that for an event of this kind in this field [a set of background conditions] there is some cause, and if the cause is not such-and-such, we cannot see what else the cause may be.' (1967, p. 332). 
The late Mill endorsed the view that the Canons generate revisable causal conclusions. This take on the Canons is in line with Mill's later fallibilist epistemology (see Jacobs 1991). In a seminal paper, Struan Jacobs has rightfully argued that the rôle of the inductive Canons in Mill's later meta-scientific view became restricted to criteria of inductive justification (by contrast, according to his earlier views, the Canons were also precepts of discovery) (ibid., p. 81). ${ }^{2}$ Jacobs' account nuances the view defended by J. M. Robson, the editor of Mill's Collected Works, who claims that the revisions in Mill's System 'do not [...] reveal a shift in attitudes; rather, they typically consist of answers to opponents, or new illustrations of methods' (1973, p. lxxvii).

Mill's changing views on the certainty of knowledge can be gleaned from the revisions he made in various editions - as Mill never uniformly revised A System of Logic, the final version, quite inconsistently, contains both talk of absolute and provisional certainty/causes. For instance, in the press copy, the first edition and the second edition (1846), Mill wrote that we can consider inductions 'as absolutely certain and absolutely universal', that they attain 'absolute certainty', that sound inductions 'amount to full proof', and that inductions are based on previous 'inductions of unquestionable certainty', while in later editions he tempered these statements respectively into 'quite certain and quite universal', 'certainty' tout court, 'amount practically to proof', and 'inductions deserving of reliance' (1843/1872, III.iv.3, III.iii.2, III.iv.2; 1973, p. 322 (note $n$ and p), p. 312 (note e), p. 319 (note g)). From the 1851 edition onwards he replaced 'different antecedents must be set down as distinct causes' into 'different antecedents must be set down

${ }^{2}$ Cf. Johnson 1922, p. 200. Ernst Nagel pointed out that Mill's failure to carefully differentiate between finding rules of discovery and funding general criteria of validity caused major confusion (Nagel's introduction in 1950, p. xxxix). 
provisionally as distinct causes' (1843/1872, III.x.3; 1973, p. 439 (note $e)$ ).

The early Mill aimed to establish absolutely certain knowledge. For instance, in the press copy manuscript (1842) Mill wrote on the Canons, as follows:

So long as any doubt hung over this fundamental principle [the Law of Causality], the various Methods of Induction which took that principle for granted could only afford results which were admissibly conditionally; as showing what law the phenomena under investigation must follow if it is followed any fixed law at all. As, however, when the rules of correct induction had been conformed to, the result never failed to be verified by all subsequent experience; every such inductive operation had the effect of extending the acknowledged dominion of general laws, and bringing an additional portion of the experience of mankind to strengthen the evidence of the universality of the law of causation: until now at length we are fully warranted in considering that law, as applied to all phenomena within the range of human observation, to stand on equal footing in respect to evidence with the axioms of geometry itself. (1843/1872, III.xxi.3; 1973, p. 571 (note i) [emphasis added])

For Mill the Law of Causality was an absolute truth and, by consequence, the methods of induction based upon it provide results that are true and unconditional (and thus absolute). He insisted that inductions will never fail to be verified in future inquiry. Mill claimed that the Canons generate absolutely certain results: once applied, they yield unrevisable knowledge. ${ }^{3}$ This contrasts strongly with the late Mill who wrote the following in the 1872 edition:

In matters of evidence, as in all other human things, we neither require, nor can attain, the absolute. We must hold even our strongest convictions with an opening left in our minds for the

\footnotetext{
${ }^{3}$ Compare with the early draft of $A$ System: 'We have next to enquire into the nature and grounds of Induction; the conditions necessary to constitute a perfect, or conclusive Induction' (1974, p. 1102). 
reception of facts which contradict them; and only when we have taken this precaution, have we earned the right to act upon our convictions with complete confidence when no such contradiction appears. Whatever has been found true in innumerable instances, and never found to be false after due examination in any, we are safe in acting on as universal provisionally, until an undoubted exception could scarcely have escaped notion. (1843/1872, III.xxi.4; 1973, p. 574 [emphasis added])

It then comes as a natural consequence that the late Mill came to see the results harvested by the Canons of induction as revisable conclusions. Assurance that no exceptions will occur comes 'in a very moderate degree' (1843/1872, III.iii.2; 1973, p. 312). Mill became increasingly aware of the difficulties one encounters when trying to apply the Canons of Induction, i.e. he became increasingly aware that the highly idealized conditions that the Canons of Induction presuppose can hardly be met in the real world, in view of the Plurality of Causes and Intermixture of Effects (see infra).

\section{Mill's System of Logic}

According to Scarre, J.S. Mill's A System of Logic embodied 'the greatest revolution in logical studies since Aristotle' (1987, p. 1). ${ }^{4}$ As all scientific inference consists of inductions (i.e. inference to general propositions) or interpretations of inductions (i.e. inference to individual facts), clarifying 'What induction is (..) and what conditions render it legitimate' is, according to John S. Mill, 'the main question of the science of logic' (1843/1872, III.i.1; 1973, p. 283). Logic is the judge of all particular investigations (1843/1872, Intro. $\$ 5 ; 1973$, p. 10). Mill initially defined induction as the operation of discovering and proving general propositions

${ }^{4}$ As I shall abstract here from the rôle of logic in Mill's overall empiricist project, I refer the reader to Scarre's study (1987, chapters 6-9). 
(1843/1872, III.v.1; 1973, p. 325) 'by which we infer that what we know to be true in a particular case or cases, will be true in all cases which resemble the former in certain assignable respects' (1843/1872, II.ii.1; 1973, p. 288). After Whewell's objections to the Canons of Induction he presented them as methods of proof only (Courtney 1889, p. 82).

General conceptions obtained by induction derive from observation only and are in the facts (1843/1872, IV.i.2; 1974, pp. 650-653). They are neither pre-existent nor constructed by the mind out of its own materials $\left(1843 / 1872\right.$, II.ii.4; 1973, p. 296). ${ }^{5}$ Logic is concerned with inference, not with intuitive truths (1843/1872, Intro. $\$ 4 ; 1973$, p. 6). According to Mill the Logic of Induction is a Universal Logic: it applies to every day life as well as scientific reasoning. In both cases the process is essentially the same. Mill speaks of a general proposition in cases where a predicate is affirmed or denied of an unlimited number of phenomena (1843/1872, I.v.1, III.ii.2; 1973, p. 89, p. 289). More generally, induction is 'inferring a proposition from propositions less general than itself' (1843/1872, II.i.3; 1973, p. 162), so that the conclusion contains more information than what was originally contained in the premises. Mill noted that accepting a generalization meant that 'the falsity of the generalization would be inconsistent with the constancy of causation' (1865/1866[1969], p. 293). ${ }^{6}$

To Mill's contemporaries, the distinction between deduction and induction was not as straightforward as it is today, neither was it a communis opinio that true inference, expressed by real propositions, is inductive and that deduction, expressed by 'verbal' propositions, is

${ }^{5}$ No Whewellian super-induction is required (1843/1872, III.ii.4-5; 1973, pp. 294-305. For a critical survey of the Mill-Whewell debate, see Snyder 1997 and Snyder 2006.

${ }^{6}$ Between 1841 and 1946 Comte and Mill corresponded intensely (see Leroux 1877). Mill's canons are only cursory mentioned by Comte (ibid., pp. 199200; see also: Guillin 2007, pp. 14-18 [the author is indebted to Vincent Guillin for this reference]. 
only apparent inference. ${ }^{7}$ Real propositions report on matters of fact (e.g. 'Archbishop Whately died at 10 p.m.'), while verbal propositions report on the meaning of terms (e.g. 'humans are mortal'). On Mill's account, 'the business of Inductive Logic is to provide rules and models (such as the Syllogism and its rules are for ratiocination) to which if inductive arguments conform, those arguments are conclusive, and not otherwise' (1843/1872, III.ix.6; 1973 , p. 430). He clearly aimed at a normative theory of induction. In the introduction to A System of Logic Mill added: 'I do not attempt to decompose the mental operations in question into their ultimate elements. It is enough of the analysis as far as it goes is correct, and if it goes far enough for practical purposes' (1843/1872, III. Intro. §7; 1973 , p. 12). ${ }^{8}$ The key issue is namely to clarify why a single instance, in some cases, is sufficient for a complete induction, while in others, a myriad of concurring instances, cannot establish a single universal proposition (1843/1872, III.iii.3; 1973, p. 314). Mill's point of departure was the observation that in the course of the history of science we have established inductions: 'it is because there are such, that a Logic of Induction is possible’ (1843/1872, III.iv.3; 1973, p. 322 [emphasis added]). Mill often stressed that the formulation of the Logic of Induction presupposes sufficient knowledge about the actual history of science - in this respect he was, as he himself admitted (1843/1872, III.i.2; 1973, p. 284 (note c)), less qualified than William Whewell who knew the history of science intimately as his History of the Inductive Sciences (first edition: 1837) testifies. One of the chief goals of logic is to ascertain whether a belief is well founded and to judge evidence. As Mill wrote in a draft version of his System: 'The province of Logic is not the evidence itself, but the operation of

\footnotetext{
${ }^{7}$ See especially Scarre 1987, pp. 15ff. According to Richard Whately, induction was a deduction from instances (1849 [1826], pp. 253-254). According to Augustus De Morgan, complete induction yielded demonstrative knowledge, while 'normal' induction yielded only probable knowledge (1847, p. 211).

8 Cf. Mill's Inaugural Delivered in the University of St. Andrews, in $1867 / 1867[1984]$, pp. 237-240.
} 
the understanding in judging the evidence' (1974, p. 965, cf. p. 967). ${ }^{9}$ Logic is the test of our reasoning, it is the Science of the Conditions of Correct Reasoning' (1865/1867[1979], p. 361) (or ars artium, as Mill sometimes referred to it). In Chapter VIII, entitled 'Of the Four Methods of Experimental Inquiry', of Book III on induction Mill described the four 'only possible modes of experimental inquiry', which 'compose the available resources of the human mind for ascertaining the laws of succession of phenomena' (1843/1872, III.viii. 7; 1973, p. 406).

The ground of induction is the Axiom of the Uniformity of Nature, the 'ultimate major' in our inductive reasoning (1843/1872, III.iii. 1 ; 1973, p. 308), which is derived from enumerative induction (1843/1872, III.iii.1; 1973, pp. 306-307). This Axiom is not universally true, since the course of nature is not always uniform (1843/1872, III.iii.2; 1973, p. 311). Yet 'it is enough that it pervades the particular class of phenomena to which the induction relates' (1843/1872, III.iii.1; 1973, p. 310). Mill noted that we can only have assurance of it 'in a very moderate degree' (1843/1872, III.iii.2; 1973, p. 312). Scarre has noted that Mill was being inconsistent and 'seems not to have grasped what Hume's problem was' $\left(1998\right.$, p. 116) ${ }^{10}$. Leaving this issue aside, according to Mill, there was no paradox in his criticism of enumerative induction and his acceptance of enumerative induction as the foundation of the uniformity of nature (see Ryan 1974, p. 83). ${ }^{11}$ He asserted that 'we are justified in the seeming inconsistency, of holding induction by simple enumeration to be good for proving this general truth, the foundation of scientific induction, and yet refusing to rely on it for any of the narrower inductions' (1843/1872, III.iii.3; 1973, p. 571) and that 'the major premise [the uniformity of nature] is not the proof of

${ }^{9}$ Cf. Mill to Thomas Carlyle, 2 March 1834 (Mill 1812/1848[1963], vol. 12, p. 219). For a convincing psychologistic reading the deductive logic of Mill, see Godden 2005.

${ }^{10}$ Cf. Scarre 1987, p. 87 , pp. 100-103.

${ }^{11}$ Cf. 1843/1872, III.iv.3, III.xxi.1-2; 1973, p. 320, pp. 563-568. 
the conclusion, but is itself proved, along with the conclusion from the same evidence' (1843/1872, III.xxi.4; 1973, p. 572 [emphasis added]).

Mill's theory of induction was based on his concept of cause:

The notion of Cause being the root of the whole theory of Induction, it is indispensable that this idea should, at the very outset of our inquiry be, with the utmost practicable degree of precision, fixed and determined. (1843/1872, III.v.2; 1973, p. 326)

A cause is the assemblage of its (physical and proximate) conditions (1843/1872, III.v.3; 1973, pp. 326-327). Mill noted that it is seldom that a single antecedent causes a consequent:

It is seldom, if ever, between a consequent and a single antecedent, that this invariable sequence subsists. It is usually between a consequent and the sum of several antecedents; the concurrence of all of them being requisite to produce, that is, to be certain of being followed by, the consequent. In such cases it is very common to single out one only of the antecedents under the denomination of Cause, calling the others merely Conditions. Thus, if a person eats of a particular dish, and dies in consequence, that is, would not have died if he had not eaten of it, people would be apt to say that eating of that dish was the cause of his death. There needs not, however, be any invariable connexion between eating of the dish and death; but there certainly is, among the circumstances which took place, some combination or other on which death is invariably consequent: as, for instance, the act of eating of the dish, combined with a particular bodily constitution, a particular state of present health, and perhaps even a certain state of the atmosphere; the whole of which circumstances perhaps constituted in this particular case the conditions of the phenomenon, or, in other words, the set of antecedents which determined it, and but for which it would not have happened. (1843/1872, III.v.3; 1973, pp. 327-328) 
'Philosophically speaking' we have 'no right to give the name of cause to one of them, exclusively of the others' (1843/1872, III.v.3; 1973, p. 328). According to Mill, the eating of the dish is an event, i.e. an instantaneous change or succession of instantaneous change, while the various other conditions are states possessing more or less of permanency. Note that Mill never formulated a criterion for instantaneous changes.

Mill considers the cause of a phenomenon as the sum or assemblage of all conditions either (i) required to produce the consequent (or effect) or (ii) without which it would not have happened (1843/1872, III.v.3; 1973, pp. 327-328). By (i) $C \supset E$ obtains and by (ii) not- $C \supset$ not- $E$ (equivalent to $E \supset C$ ) obtains. Mill conceived of nature as a web composed of distinct threads (1843/1872, III.iv.1; 1973, p. 318). A cause is, according to Mill, an unconditional invariable antecedent, i.e. an antecedent which produces its effect invariably and is unconditional upon any other antecedent. ${ }^{12}$

\section{The Presuppositions of Mill's Canons}

Here we unravel the presuppositions of Mill's Canons of Induction. I shall use formal expressions to do so. Contrary to previous attempts ${ }^{13}$, I aim to stay as close as possible to Mill's original proposal. J.L. Mackie has suggested that there is not one method of agreement, one method of difference, but a series of variants of each (1967, p. 325). One can certainly develop variants of Mill's methods, but Mill himself never did so. Moreover, he stressed quite strongly

\footnotetext{
${ }^{12}$ See Mackie 1980 , p. 83 for a counterexample. Consider the case where $\mathrm{C}$ is a common cause of $\mathrm{A}\left(\right.$ at $\left.t_{1}\right)$ and $\mathrm{B}$ at $\left(t_{1+n}\right)$ : nothing prevents $\mathrm{A}$ from being a cause of B.

13 See Schock 1965, pp. 235-240 and Czerwinski 1960 [the author is indebted to Diego L. Rosende for these references].
} 
that ' $[\mathrm{t}]$ he four methods which it has now been attempted to describe, are the only possible modes of experimental inquiry - of direct induction à posteriori, as distinguished from deduction: at least, I know not, nor am able to imagine, any others' (1843/1872, III.viii.7; 1973 , p. 406). Here I deal with Mill's original formulations not with the variants later added by Mackie. It should be kept in mind that no full-blown logic of Millian induction is provided, only a formalization of the inference rules of Mill's Canons of Induction as a means of elucidating.

The first method is the Method of Agreement:

\title{
FIRST CANON
}

\begin{abstract}
If two or more instances of the phenomenon under investigation have only one circumstance in common, the circumstance in which alone all instances agree, is the cause (or effect ${ }^{14}$ ) of the given phenomenon. (1843/1872, III.viii.1; 1973, p. 390)
\end{abstract}

Suppose that $A$ occurs together with $B C$ (and that the corresponding consequent is $a b c$ ) and that, next, $A$ occurs together with $D E$ (and that the corresponding consequent is ade). Then we may reason that $b$ and $c$ are not consequences of $A$ (for they were not present in ade) and similarly for $d$ and $e$. For instance, suppose that two individuals had a different lunch but that the wine they drank was mixed with a high dose of poison so that both died shortly after lunchtime. By the Method of Agreement we can then conclude that the poison in the wine caused their death. By applying the Method of Agreement we cannot establish joint causes (which conflicts with Mill's definition of cause as an assemblage of conditions; see infra), for it is assumed that two phenomena have only one circumstance in common. Furthermore, once we have established a single common

${ }^{14}$ Here Mill considers the direction of the causal relation purely logically, i.e. without reference to a time function, so that without a time ordering $X$ can be the cause of $Y$ or conversely. 
circumstance, we stop looking for other potential common circumstances.

In order to shed more light on the presuppositions of Mill's Canons, I shall present them in a more formalized version. First of all, we need to introduce a function $f$, which assigns instants of time $t^{n}$ to the observed components (c's) of a 'Millian phenomenon' (a definition of a Millian phenomenon is spelled out in just a moment) according to their succession in time (cf. Mill 1843/1872, III.v.2; 1973, p. 327). Correspondingly,

$$
(\forall \mathrm{c})\left(\exists \mathrm{t}^{\mathrm{n}}\right) f: \mathrm{c} \mapsto \mathrm{t}^{\mathrm{n}},
$$

where $\mathrm{t}^{\mathrm{n}} \in \mathbb{N}^{+}$(the set of non-negative integers starting from 0 ) and $\mathrm{t}^{\mathrm{n}}<\mathrm{t}^{\mathrm{n}+\mathrm{z}}$. The idea is that $f$ assigns instants in time to all c's according to their order of occurrence. In order to render Mill's First Canon, which is based on the intuition that whatever antecedent can be absent notwithstanding the occurrence of the consequent is not a cause of this phenomenon (1843/1872, III.viii.1; 1973, p. 390), explicit I define a Millian phenomenon ('phenomenon $x$ at time $\mathrm{t}^{\mathrm{n}}$ ) as a set of components or circumstances ${ }^{15}$ :

$$
\mathrm{p}_{\mathrm{x}}{ }^{\mathrm{tn}}={ }_{d f}\left\{\mathrm{c}_{1}^{\mathrm{tn}}, \mathrm{c}_{2}^{\mathrm{tn}}, \ldots, \mathrm{c}_{\mathrm{m}}{ }^{\mathrm{tn}}\right\}
$$

Mill noted that the axiom 'implied' in this method is: that whatever consequent can be excluded, with no other difference in the antecedents than the absence of a particular one, is the effect of that antecedent (1843/1872, III.viii.2; 1973, p. 391).

The First Canon, which has as its target necessary conditions but is 'not competent to prove causation' (1843/1872, III.ix.4; 1973, p. 423), can be expressed formally as follows (where ' $\rightarrow$ ' means 'is

15 Correspondingly, I shall not follow Mill's convention to denote antecedents and consequents by means of capitals and small caps respectively, which I find less accurate for my present purposes. 
the cause of'; the bar means 'we can inductively and provisionally conclude from the above'; ' $\vee$ ' refers to the exclusive disjunction; ' $\wedge$ ' to the conjunction; ' $\cup$ ' to the union of two sets, and ' $\neg$ ' to the absence of a component or a causal relation):

$$
\text { [Method of Agreement. }]^{16}
$$

$$
\begin{aligned}
& \text { (1) } \mathrm{p}_{1}{ }^{\mathrm{tn}} \wedge\left(\mathrm{p}_{1}{ }^{\mathrm{tn}}=\left\{\mathrm{c}_{1}{ }^{\mathrm{tn}}, \mathrm{c}_{2}{ }^{\mathrm{tn}}, \ldots, \mathrm{c}_{\mathrm{m}}{ }^{\mathrm{tn}}\right\}\right) \\
& \text { (2) } \mathrm{p}_{1}{ }^{\mathrm{tn}+\mathrm{z}} \wedge\left(\mathrm{p}_{1}{ }^{\mathrm{tn}+\mathrm{z}}=\left\{\mathrm{c}_{1}{ }^{\mathrm{tn}+\mathrm{z}}, \mathrm{c}_{2}^{\prime}{ }^{\mathrm{tn}+\mathrm{z}}, \ldots, \mathrm{c}_{\mathrm{m}}{ }^{\mathrm{tn}+\mathrm{z}}\right\}\right) \\
& \text { (3) } \mathrm{p}_{2}{ }^{\mathrm{tn}} \wedge\left(\mathrm{p}_{2}{ }^{\mathrm{tn}}=\left\{\mathrm{c}_{1}{ }^{\mathrm{tn}}, \mathrm{c}_{\beta}{ }^{\mathrm{tn}}, \ldots, \mathrm{c}_{\mathrm{K}}{ }^{\mathrm{tn}}\right\}\right) \\
& \text { (4) } \mathrm{p}_{2}{ }^{\mathrm{tn}+\mathrm{z}} \wedge\left(\mathrm{p}_{2}{ }^{\mathrm{tn}+\mathrm{z}}=\left\{\mathrm{c}_{1}{ }^{\mathrm{tn}+\mathrm{z}}, \mathrm{c}_{\beta}^{\prime}{ }^{\mathrm{tn}+\mathrm{z}}, \ldots, \mathrm{c}_{\mathrm{K}}^{\mathrm{tn}+\mathrm{z}}\right\}\right)
\end{aligned}
$$

$$
\mathrm{c}_{1}{ }^{\mathrm{tn}} \rightarrow \mathrm{c}_{1}{ }^{\mathrm{tn}+\mathrm{z}}
$$

Some explanation here: by "I refer to the fact that $C^{\prime}{ }_{x}$ is the

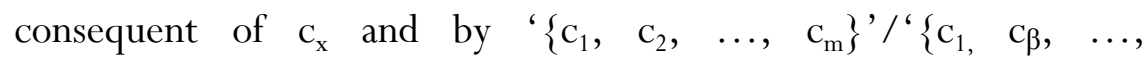
$\mathrm{C}_{\mathrm{K}}$ \}' [voetnoot verwijderd] I use different subscripts to denote different c's. If only one circumstance remains, it is the (necessary) cause $^{17}$ we are in search of $(1843 / 1872$, III.viii. 1; 1973, p. 390). The Method of Agreement remains subject to considerable doubt, Mill stressed, which arises 'from the impossibility of assuring ourselves that $A$ is the only immediate antecedent common to both instances' (1843/1872, III.viii.1; 1973, p. 390) - i.e. as $A$ might be found by

\footnotetext{
${ }^{16}$ For simplicity's sake I assume that we observe two different phenomena at the same time.

${ }^{17}$ If $A$ (antecedent) is a necessary condition of $C$ (consequent), then whenever $C$ is present $A$ is present. Hence, if $C$ was present while $A$ was absent, then $A$ is not a necessary condition of $C$. We observe that the antecedents $\mathrm{c}_{2}, \ldots$, $\mathrm{C}_{\mathrm{m}} / \mathrm{C}_{\beta}, \ldots, \mathrm{C}_{\mathrm{k}}$ can be absent despite the occurrence of $\mathrm{C}^{\prime}{ }_{1}$. In this case, none of these are necessary conditions - thus, they are 'eliminated' as causes. As $\mathrm{c}_{1}$ is the only remaining condition, it follows that $\mathrm{c}_{1}$ is a necessary condition of $\mathrm{c}_{1}{ }^{\text {'. }}$.
} 
accident (1843/1872, III.viii.1; 1973, pp. 388-389), it may turn out that $A$ is merely an invariable antecedent but not an unconditional one. ${ }^{18}$ Mill added that ' $[t]$ he conclusions which that [method] yields, when the number of instances compared is small, are of no real value, except as, in the character of suggestions' (1843/1872, III.x.2; 1973, p. 436).

The Second Canon suffers from this problem to a lesser extent, Mill claimed, for by artificially producing or preventing $A$ we are more certain that $\mathrm{A}$ is an unconditional antecedent. ${ }^{19}$ It is based on the axiom that whatever antecedent cannot be excluded without preventing the phenomenon, is the cause, or a condition, of that phenomenon (1843/1872, III.viii.2; 1973, p. 391). Mill's formulation of it is:

\section{SECOND CANON}

If an instance in which the phenomenon under investigation occurs, and an instance in which it does not occur, have every circumstance in common save one, that one occurring only in the former; the circumstance in which alone the two instances differ, is the effect ${ }^{20}$ or the cause, or an indispensable 21 part of the cause, of the phenomenon. (1843/1872, III.viii.2; 1973, p. 391)

If we, for instance, observe $A B C$ and its consequent $a b c$ and $A B C$ and its consequent $a b c$, we may infer that $A$ is the cause of $a$, for when $A$ was not present a did not occur. Suppose that we investigate an

\footnotetext{
${ }^{18}$ For further problems with this Canon, see the amusing case of the 'scientific drinker' (Cornish 1997, p. 65).

${ }^{19}$ Mill observed: 'It is, however, much easier to analyse completely a set of arrangements made by ourselves, than the whole complex mass of the agencies which nature happens to be exerting at the moment of the production of a given phenomenon. We may overlook some of the material circumstances in an experiment with an electrical machine; but we shall, at the worst, be better acquainted with them than with those of a thunder-storm.' (1843/1872, III.viii.1; 1973, p. 390).

${ }^{20}$ See footnote 14 .

${ }^{21}$ I.e., 'necessary' (1843/1872, III.viii.2; 1973, p. 391 (note f)).
} 
electrical circuit. If we turn the switch we observe that a light bulb is lighted; if we do not turn the switch the bulb is not lighted. By the Method of Difference we may conclude that, other things being equal, the turning of the switch is the cause of the lightening of the bulb.

Mill's Method of Difference requires that one and the same antecedent was present before the positive instance of the consequent and absent before the negative instance of the consequent. The Second Canon which has as its target a sufficient cause $^{22}$, can be formalised, as follows:

\section{[Method of Difference.]}

$$
\begin{aligned}
& \text { (1) } \mathrm{p}_{1}{ }^{\mathrm{tn}} \wedge\left(\mathrm{p}_{1}{ }^{\mathrm{tn}}=\left\{\mathrm{c}_{1}{ }^{\mathrm{tn}}, \mathrm{c}_{2}{ }^{\mathrm{tn}}, \ldots, \mathrm{c}_{\mathrm{m}}{ }^{\mathrm{tn}}\right\}\right) \\
& \text { (2) } \mathrm{p}_{1}{ }^{\mathrm{tn}+\mathrm{z}} \wedge\left(\mathrm{p}_{1}{ }^{\mathrm{tn}+z}=\left\{\mathrm{c}_{1}{ }^{\mathrm{tn}+z}, \mathrm{c}_{2}{ }^{\mathrm{tn}+z}, \ldots, \mathrm{c}_{\mathrm{m}}{ }^{\mathrm{tn}+z}\right\}\right) \\
& \text { (3) } \mathrm{p}_{2}{ }^{\mathrm{t}} \wedge\left(\mathrm{p}_{2}{ }^{\mathrm{tn}}=\left\{\neg \mathrm{c}_{1}^{\mathrm{tn}}, \mathrm{c}_{2}{ }^{\mathrm{tn}}, \ldots, \mathrm{c}_{\mathrm{m}}{ }^{\mathrm{tn}}\right\}\right) \\
& \text { (4) } \mathrm{p}_{2}{ }^{\mathrm{tn}+\mathrm{z}} \wedge\left(\mathrm{p}_{2}{ }^{\mathrm{tn}+z}=\left\{\neg \mathrm{c}_{1}{ }^{\mathrm{tn}+z}, \mathrm{c}_{2}{ }^{\mathrm{tn}+z}, \ldots, \mathrm{c}_{\mathrm{m}}{ }^{\mathrm{tn}+z}\right\}\right)
\end{aligned}
$$

$$
\left(\mathrm{c}_{1}{ }^{\mathrm{tn}} \rightarrow \mathrm{c}^{\prime}{ }_{1}{ }^{\mathrm{tn}+\mathrm{z}}\right) \vee\left(\left(C \cup\left\{\mathrm{C}_{1}{ }^{\mathrm{tn}}\right\}\right) \rightarrow \mathrm{c}^{\prime}{ }_{1}{ }^{\mathrm{tn}+\mathrm{z}}\right)
$$

However, Mill's Canons suffer from two fundamental drawbacks. First, as the Method of Difference only establishes single antecedents as causes, it cannot accommodate cases of Intermixture of Effects (see infra). Furthermore, joint causes are not derivable. Secondly, on the assumption that negatives cannot produce change, $A B \rightarrow a$, for

${ }^{22}$ If $A$ is a sufficient condition of $C$, then whenever $A$ is present $C$ is present. Hence, if $A$ is present while $C$ is absent, then $A$ is not a sufficient condition of $C$. We observe that $\mathrm{c}_{2}, \ldots, \mathrm{C}_{\mathrm{m}}$ can be present while $\mathrm{c}_{1}^{\prime}$ is absent. In this case, none of these components are sufficient conditions - thus, they are 'eliminated' as causes. As $\mathrm{C}_{1}$ is the only remaining condition, it follows that $\mathrm{C}_{1}$ is a sufficient condition of $\mathrm{C}^{\prime}{ }_{1}$. 
instance, never obtains. Mill wrote that 'every fact or phenomenon which has a beginning, invariably arises when some certain combination of positive facts exists, provided certain other positive facts do not exist (1843/1872, III.v.3; 1973, p. 330 [emphasis added]). Furthermore, Mill's Method of Difference a fortiori excludes both simultaneous causation (1843/1872, III.v.8; 1973, p. 344), which maintains when cause and effect occur contemporaneously, and permanent causation, which refers to causal factors which cannot be eliminated - the exclusion of such cases is, by the way, obvious in view of Mill's distinction between uniformities of succession and uniformities of coexistence (the former refer to phenomena that are directly causally related; the later refer to phenomena that are produced by a common cause) (1843/1872, III.v. 1; 1973, p. 323).

Although the Method of Difference, which is a method of artificial experiment, is 'a still more potent instrument of the investigation of nature' (1843/1872, III.viii.1; 1973, p. 390) than the Method of Agreement, which we employ in cases where experimentation is impossible, it is by no means waterproof, as Mill noted:

If we could be certain of having ascertained all the invariable antecedents [by the Method of Agreement], we might be sure that the unconditional invariable antecedent; or cause, must be found somewhere among them. Unfortunately, it is hardly ever possible to ascertain all the antecedents, unless the phenomenon is one in which we can produce artificially. Even then, the difficulty is merely lightened, not removed. (1843/1872, III.viii.1; 1973, p. 390)

In the spontaneous operations of nature there is generally such complication and such obscurity, they are mostly either on so overwhelmingly large or on so inaccessibly minute a scale, we are ignorant of a great part of the facts which really take place, and even of those which we are not ignorant are so multitudinous, and therefore so seldom exactly alike in any two cases, that a spontaneous experiment, of the kind required by the Method of 
Difference, is commonly not to be found. (1843/1872, III.viii.3;

1973, pp. 392-393)

If we can successfully apply the Method of Difference to an artificially produced experiment, we have ascertained at least one invariable antecedent or consequent, 'however many other invariable antecedents or consequents may still remain unascertained' (1843/1872, III.viii.3; 1973, pp. 393-394). In such manner, a 'progressive localization of a cause' is obtainable (Mackie 1980, p. 72).

It should be noted that - and this was not sufficiently stressed (although at some times implicitly assumed (e.g. Mill 1843/1872, III.v.3; 1973, p. 328)) by Mill himself -that we cannot say that we have derived that $A$ is the cause of $d$ universally, but rather that $A$ is the cause of $d$, under condition $B C$ (Hobhouse 1890, p. 259). J.L. Mackie also stressed this by calling attention to the notion of a '(causal) field', i.e. a set of specifiable background conditions: '[t]he causal field in this sense is not itself even part of a cause, but is rather a background against which the causing goes on' (1980, p. 63). According to Mackie, (Millian) causes are what make the difference in relation to some background or causal field (ibid., p. xi). For instance, when we attempt to explain a disease we are not concerned not with the cause of disease in general, but with what causes disease in human beings on earth, breathing air, eating food, etc (ibid., p. 325).

Mill concluded that the Method of Difference is the sole method by which we can 'arrive with certainty at causes' (1843/1872, III.viii.3; 1973, p. 394). A single instance eliminating some antecedent is of more value than the greatest multitude of instances. From at least 1862, Mill became aware of the most important limitations and difficulties of his Canons: they assumed that every effect is 'connected exclusively with a single cause, that every fact is incapable of being mixed and confounded with another coexistent effect' ((1843/1872, III.x.1; 1973, p. 434) and that the 
reduction of phenomena to formulae is an obvious given. ${ }^{23}$ In similar vein, he wrote that the Inductive Sciences 'in virtue of the peculiar character of one indispensable portion of the general formulæ according to which their inductions are made, [are also] Hypothetical Sciences. Their conclusions are only true on certain suppositions, which are, or ought to be, approximations to the truth, but are seldom, if ever, exactly true' ((1843/1872, III.vi.1; 1973, p. 253). $A b$ initio the Canons suppose that we are given a finite set of enumerable alternatives. Mill's Canons suppose 'an ideal analysis of the evidence for inductive conclusions' (Nagel 1950, p. xli).

Plurality of Causes renders the Method of Agreement uncertain, since we assume that the circumstance shared in both consequents must have been produced in both instances by the same cause (1843/1872, III.x.2; 1973, p. 435). Intermixture of Effects, where different causes are not 'separately producing each its own effects, but interfering with or modifying the effects of the other' (1843/1872, III.x.4; 1973, p. 440), makes the Method of Difference 'entirely unavailing', since other causes than the one established have been operating during the transition (1843/1872, III.x.8; 1973, p. 451). In such cases the Inverse Deductive Method, in which one deduces what should happen in complex cases from what is known about simple cases and then inductively tests these deductions, is the only option. Mill uses the composition of forces in mechanics as an analogy. Mill ignores the relations by which complex cases are built up from the simple cases (i.e. he assumes that Intermixture of Effects does not occur) and thinks of the inference as an instance of what is now called the deductive rule of conjunction, whereas one needs a

${ }^{23}$ See e.g. Venn 1907 [1889], pp. 416-417, Laurie 1893, p. 324 and Whewell 2001 [1860], vol. 7, p. 263. In 1957 the assistant editor of Science, Joseph Turner, commented on Mill's canons, as follows: 'Of course, given a set of variables, $A, B, C$, and $D$, you can examine mechanically all possible combinations in search for invariable relationships. But to decide in the first place what variables are relevant to the problem requires an insight for which no rules are available.' (1957, p. 431). 
special empirical law (often called a 'composition law') which takes account of the relations among the parts in the complex cases. The Inverse Deductive Method consists of three consecutive stages: (i) a first stage in which the laws of (concurrent) cause are ascertained by the four methods discussed previously, (ii) a second stage, in which it is determined from the laws of the causes what effect any given combination of those causes will produce (by a deductive rule of conjunction), and (iii) a third stage in which the deduction obtained in (ii) are verified (1843/1872, III.xi.1-3; 1973, pp. 454-563). The Hypothetical Method consists of only (ii) and (iii) (1843/1872, III.xiv.4; 1973, p. 492). Mill wrote:

In general, the laws of causes on which the effect depends may be obtained by an induction from comparatively simple instances, or, at the worst, by deduction from the laws of simpler causes, so obtained. By simple instances are meant, of course, those in which the action of each cause was not intermixed or interfered with, or not to any great extent, by other causes whose laws were unknown. And only when the induction which furnished the premises to the Deductive Method rested on such instances, has the application of such a method to the ascertainment of the laws of a complex effect, been attended with brilliant results. (1843/1872, III.xi.1; 1973, p. 458 [emphasis added])

On a more abstract level, the Canons further presupposes that: (i) antecedents and consequents are correlated deterministically ( $=$ the principle of determinism ${ }^{24}$ ), (ii) the true antecedent is among those we have examined (= the principle of limited variety), (iii) backwards causation is impossible, and, finally, (iv) an event ontology, in which it is supposed that (iv.i) pure negatives cannot be considered as

${ }^{24}$ Charles M. Douglas stated: 'Induction goes on the supposition that everything is completely caused, or is ideally capable of being presented as an effect or product of conditions.' (1888, p. 68). Mill accepted the Law of Causation, according to which whatever has a beginning has a cause, as valid (1843/1872, III.v.1; 1973, p. 325). Cause and effect do not need to be contiguous (1843/1872, III.xiv.6; 1973, p. 505). 
causes, (iv.ii) there is no Intermixture of Effects (in other words, it is assumed that an effect is always compounded homogeneously so that a joint effect is composed of the sum of the separate effects (1843/1872, III.vi.3; 1973, p. 376)) and (iv.iii) there is no Plurality of Causes (i.e. that the same effect is always caused by the same cause). ${ }^{25}$ Mill noted that a cause philosophically speaking is the sum of the positive and negative conditions taken jointly (1843/1872, III.v.3; 1973, p. 332). These negative conditions may be denoted by a single term: 'the absence of preventing or counteracting causes' (ibid.). Note that Mill stressed that 'From nothing, from a mere negation, no consequences can proceed' (1843/1872, III.v.3; 1973, p. 330). Both the Method of Difference and the Method of Agreement assume that a single consequent (effect) is produced by a single antecedent (cause) - this assumption is in conflict with Mill's definition of a cause as an assemblage of conditions (cf. 1843/1872, III.x.1; 1973, p. 434). From the 1862 edition onwards, Mill seems to be aware of that, since he added: 'The cause indeed may not be simple; it may consist of an assemblage of conditions; but we have supposed that there was only one possible assemblage of conditions, from which the given effect could result' (1843/1872, III.x.1; 1973, p. 434)

Some phenomena do not allow the antecedents to be separated from each other. In such cases, we turn to the Joint Method of Agreement and Difference or the Indirect Method of Difference:

\section{THIRD CANON}

If two or more instances in which the phenomenon occurs have only one circumstance in common while two or more instances in which it does not occur have nothing in common save the absence of that circumstance; the

${ }^{25}$ See 1843/1872, III.v.7-9; 1973, pp. 342-348. Mackie notes: 'our reasoning does not (...) exclude factors as irrelevant, but positively locates some at least of the relevant factors within the differentiating cluster' (1980, p. 72). 
circumstance in which alone the two sets of instances differ, is the effect, or the cause, or an indispensable part of the cause, of the phenomenon. (1843/1872, III.viii.4; 1973, p. 396)

This method is an improvement of the Method of Agreement, but it does not participate in 'the more cogent nature of the Method of Difference' (ibid.), since the requisitions of the Method of Difference are not met. This method can be formalized by a combination of the formalizations I have provided earlier.

The Canons discussed above are guidelines for the establishment of causes. The Fourth assumes that we have established some causes. The Method of Residues, a modification of the Method of Difference, goes as follows:

\section{FOURTH CANON}

Subduct from any phenomenon such part as is known by previous inductions to be the effect of certain antecedents, and the residue of the phenomenon is the effect of the remaining antecedents. (1843/1872, III.viii. 5; 1973, p. 398)

When we have established, by previous inductions founded on the Method of Difference, that certain consequents of a phenomenon are the effects of certain corresponding antecedents, we may conclude that the remaining consequents are caused by some yet unknown antecedents. This method is 'the most fertile in unexpected results', because it draws our attention to 'sequences in which neither the cause nor the effect were sufficiently conspicuous to attract themselves the attention of observers' (ibid.). Suppose we observe the behaviour of a metal rod. Suppose that we try to explain the behaviour of the rod by the law of universal gravitation and that we notice that the motion of the rod differs from the predictions by the law of universal gravity. The residual motion of the rod, i.e. the motion superadded to its gravitational motion, then needs to be 
explained by (an) additional force(s). The residual motion equals the overall effect minus the gravitational effect. Formally:

$$
\text { [Method of Residues.] }
$$

$$
\begin{aligned}
& \text { (1) } \mathrm{p}_{1}{ }^{\mathrm{tn}}=\left\{\mathrm{c}_{1}{ }^{\mathrm{tn}}, \mathrm{c}_{2}^{\mathrm{tn}}, \ldots, \mathrm{c}_{\mathrm{m}}{ }^{\mathrm{tn}}\right\} \\
& \text { (2) } \mathrm{p}_{1}{ }^{\mathrm{tn}+\mathrm{z}}=\left\{\mathrm{c}_{1}{ }^{\mathrm{t}+\mathrm{z}+\mathrm{z}}, \mathrm{c}_{2}{ }^{\mathrm{tn}+\mathrm{z}}, \ldots, \mathrm{c}^{\prime}{ }_{\mathrm{m}}{ }^{\mathrm{tn}+z}\right\} \\
& \text { (3) } \mathrm{c}_{1}{ }^{\mathrm{tn}} \rightarrow \mathrm{c}^{\prime}{ }_{1}{ }^{\mathrm{tn}+\mathrm{z}}
\end{aligned}
$$

$$
\left\{\mathrm{c}_{2}{ }^{\mathrm{tn}}, \ldots, \mathrm{c}_{\mathrm{m}}{ }^{\mathrm{tn}}\right\} \rightarrow\left\{\mathrm{c}_{2}{ }^{\mathrm{tn}+\mathrm{z}}, \ldots, \mathrm{c}_{\mathrm{m}}{ }^{\mathrm{tn}+\mathrm{z}}\right\}^{26}
$$

This Canon assumes the compositionality of causes: the joint effect of causes is the sum of separate effects (1843/1872, III.vi.2; 1973, p. 373). In his Autobiography Mill wrote that, by early 1830: 'On examining, accordingly, what the mind does when it applies the principle of the Composition of Forces, I found that it performs a simple act of addition. It adds the separate effect of the one force to the separate effect of the other, and puts down the sum of these separate effects as the joint effect. But is this is a legitimate process? In dynamics, and in all mathematical branches of physics, it is; but in some other cases, as in chemistry, it is not; and I then recollected that something not unlike this was pointed out as one of the distinctions between chemical and mechanical phenomena, in the introduction to that favourite of my boyhood Thomson's System of Chemistry $^{27}$. (...) I now saw, that a science is either deductive or experimental, according as, in the province it deals with, the effects of causes when conjoined, are or are not the sums of the effects which the same causes

\footnotetext{
${ }^{26}$ In future research, one can potentially establish which antecedent is the necessary or sufficient cause of a certain consequent by resorting to the Method of Agreement or the Method of Difference, respectively.

${ }^{27}$ The reference Mill refers to can be found in Thomson 1810, pp. 2-3. He first read this work in 1816.
} 
produce when separate.' (Cockshut 1992, p. 87 [emphasis added]). ${ }^{28}$ As noted previously, the preceding Canons cannot deal with Permanent Causes, i.e. 'indestructible natural agents, which it is impossible either to exclude or to isolate' (1843/1872, III.viii.6; 1973, p. 398). In such cases, we must turn to the Method of Concomitant Variations, which applies to uniform ${ }^{29}$ variations of quantity only:

\section{FIFTH CANON}

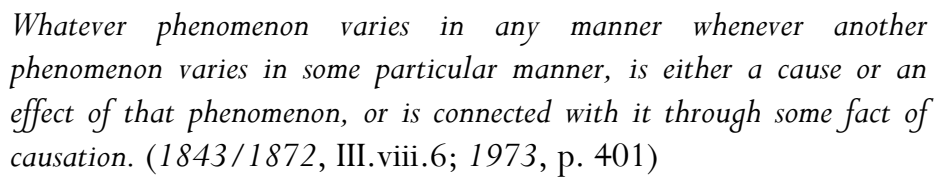

The Canon is based in the premise that the cause and effect are always proportional. Suppose we observe that a linear increase of a variable is always accompanied by the same linear increase of another variable (or that the linear decrease of a variable is always accompanied by the same linear decrease of another variable). In this case there are three options: the first variable causes the second, the second is the cause of the second, or both are dependent on an unknown common cause. Formally this can be formulated as follows, where i.y stand for a quantity (pertaining to a circumstance) being increased by a factor and $i / y$ stands for a quantity being decreased by a factor:

\section{[Method of Concomitant Variation.]}

(1) $\mathrm{p}_{1}{ }^{\mathrm{tn}} \wedge \mathrm{p}_{1}{ }^{\mathrm{tn}}=\left\{\mathrm{c}_{1(\mathrm{i})}{ }^{\mathrm{tn}}, \mathrm{c}_{2}{ }^{\mathrm{tn}}, \ldots, \mathrm{c}_{\mathrm{m}}{ }^{\mathrm{tn}}\right\}$

(2) $\mathrm{p}_{2}{ }^{\mathrm{tn}} \wedge \mathrm{p}_{2}{ }^{\mathrm{tn}}=\left\{\mathrm{c}_{\mathrm{c}_{(j)}}{ }^{\mathrm{tn}}, \mathrm{c}_{\beta}{ }^{\mathrm{tn}}, \ldots, \mathrm{c}_{\mathrm{K}}{ }^{\mathrm{tn}}\right\}$, where $i$ and $j$ are quantitative measures of one component of two different phenomena, respectively

\footnotetext{
${ }^{28}$ See further: Hausman 1995.

${ }^{29}$ Cf. 1843/1872, III.viii.6; 1973, p. 402.
} 


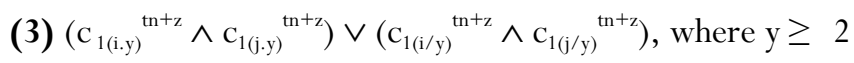

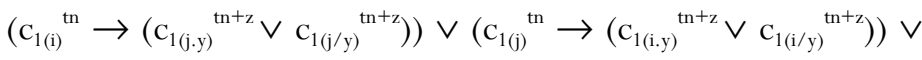

$$
\begin{aligned}
& \left(\left(\exists C^{\mathrm{tn}}\right) \rightarrow\left(\left(\mathrm{c}_{1(\mathrm{i} \cdot \mathrm{y})}{ }^{\mathrm{t}+\mathrm{z}} \wedge \mathrm{c}_{1(\mathrm{j} \cdot \mathrm{y})}{ }^{\mathrm{t}+\mathrm{z}}\right) \vee\left(\mathrm{c}_{1 \mathrm{i} / \mathrm{y})}{ }^{\mathrm{t}+\mathrm{z}} \wedge \mathrm{c}_{1 \mathrm{j} / \mathrm{y})}{ }^{\mathrm{t}+\mathrm{z}}\right)\right)\right),
\end{aligned}
$$

where $C$ is a yet undiscovered common cause

By (3) we denote that when quantity $i$ changes (diminishes of increases) $j$ does so accordingly. So both quantities are multiplied or divided by the same factor. This factor cannot be 0 or 1 . ' ${ }^{{ }^{1(i)}}{ }^{\text {tn }} \rightarrow$ $\left(\mathrm{c}_{1(\mathrm{j} . \mathrm{y})}{ }^{\mathrm{t}+\mathrm{z}} \vee \mathrm{c}_{1(\mathrm{j} / \mathrm{y})}{ }^{\mathrm{tn}+\mathrm{z}}\right)^{\prime}$ 'expresses that $\mathrm{c}_{1(\mathrm{i})}{ }^{\mathrm{tn}}$ is the cause of the changes in $j$, ' $\mathrm{c}_{1(\mathrm{j})}{ }^{\mathrm{tn}} \rightarrow\left(\mathrm{c}_{1(\mathrm{i} . \mathrm{y})}{ }^{\mathrm{tn}+\mathrm{z}} \vee \mathrm{c}_{1(\mathrm{i} / \mathrm{y})}{ }^{\mathrm{tn}+\mathrm{z}}\right)^{\prime}$ ' that $\mathrm{c}_{1(\mathrm{j})}{ }^{\mathrm{tn}}$ is the cause of the changes in $i$, and ' $\left(\exists C^{\mathrm{tn}}\right) \rightarrow\left(\left(\mathrm{c}_{1(\mathrm{i} . \mathrm{y})}{ }^{\mathrm{tn}+\mathrm{z}} \wedge \mathrm{c}_{1(\mathrm{j} . \mathrm{y})}{ }^{\mathrm{tn}+\mathrm{z}}\right) \vee\left(\mathrm{c}_{1(\mathrm{i} / \mathrm{y})}{ }^{\mathrm{tn}+\mathrm{z}} \wedge \mathrm{c}_{1(\mathrm{j} / \mathrm{y})}{ }^{\mathrm{tn}+\mathrm{z}}\right)\right)$ ' that the changes in $i$ and $j$ are caused by a yet unknown common cause.

\section{In Conclusion}

On the condition that the cause under consideration is not a permanent cause, it can potentially be dealt with by the Method of Agreement, the Method of Difference of the Joint Method of Agreement and Difference. Only these methods - among them the Method of Difference being the most certain as it presupposes an artificial experiment - potentially establish causal relations. The Method of Residues only narrows down the set of possible causes without being able to point out a single potential causal factor. It can only be applied when we have already established at least one causal relation by the Method of Difference (hence the arrow directed at the Method of Residues). If the cause under the consideration is a permanent cause and if it involves linear quantitative changes then only the Method of Concomitant Variation is at hand. The procedure of applying Mill's Canons can schematically be represented as follows: 


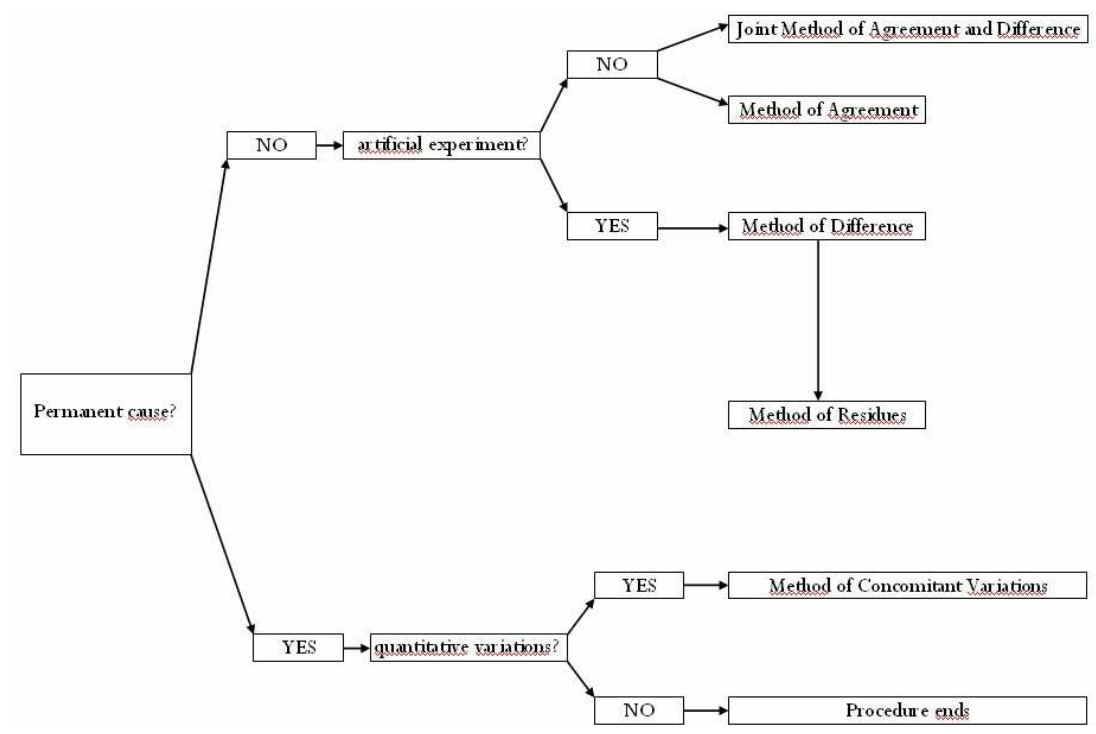

If the conditions under which inductive generalisations are valid (e.g. limited variety, no plurality of causes, no intermixture of effects, etc.) do not apply or if anomalies occur, conclusions derived from the Canons of Induction no longer follow. In other words, if we have reason to believe that the conditions (under which causal generalisation hold) are not violated and that we have not recorded an exception to our inductive generalisation we are justified in provisionally accepting the results inferred by the Canons of Induction. The key message of the later editions of The System of Logic as conceived by the late Mill was, I take it, not that by the Canons of Induction we can establish scientific certainty, but rather that they are useful in establishing causal laws in a provisional way.

\section{Acknowledgements}


The author is indebted to the Fund of Scientific Research (FWOFlanders) for financing his Postdoctoral Fellowship, to Dr Hans Lycke for useful discussion on some of the technicalities, and, finally, to several respondents to the author's query, posted on the HOPOS mailing-list, for less known Mill literature. This paper is dedicated to P.L. who loved his Mill.

\section{References}

Anschutz, R.P. 1963 [1953]. The Philosophy of J.S. Mill, Oxford: Clarendon Press. Bagehot, W. 1913. Letters on the French Coup d'État of 1851, in Literary Studies (3 vol.), London: Longmans Green And Company.

Cockshut, A.O.J., ed., 1992. The Autobiography of John Stuart Mill, Halifax: Ryburn Library Editions.

Cornish, T.A.O. 1997. 'Mill's Methods for complete Intelligent Data Analysis', in X. Liu, P. Cohen and M. Berthold, eds., Advances in Intelligent Data Analysis (IDA-97), Berlin/Heidelberg: Springer, 65-76.

Courtney, W.L. 1889. Life of John Stuart Mill, London: Walter Scott, London.

Czerwinski, Z. 1960. 'O Pojęciu Przyczyny I Kanonach Milla', Studia Logica 9, 37-62.

De Morgan, A. 1847. Formal logic, or, The calculus of inference, necessary and probable, London, Taylor and Walton.

Douglas, C.M. 1888. Analysis of Mr. Mill's System of Logic, London, Longmans, Green.

Godden, D.M. 2005. 'Psychologism in the Logic of John Stuart Mill: Mill on the Subject Matter and Foundations of Ratiocinative Logic', History and Philosophy of Logic 26, 115-143.

Guillin, V. 2007. 'La question de l'égalité des sexes dans la correspondance Comte-Mill, Une approche méthodologique', Archives de Philosophie 70, 1 19.

Hausman, D.M. 1995. 'The Composition of Economic Causes', The Monist 78, 295-307.

Hobhouse, L. T. 1890. 'Experimental Certainty', Mind, 5(58), 251-260.

Jacobs, S. 1991. 'Mill on Induction and Hypotheses', Journal of the History of Philosophy 29, 69-83.

Johnson, W.E. 1922. Logic, Part II, Demonstrative Inference: Deductive and Inductive, New York: Dover.

Laurie, H. 1893. 'Methods of Inductive Inquiry, Mind 2, pp. 319-338. 
Leroux, E., ed., 1877. Lettres d'Auguste Comte à John Stuart Mill, 1841-1846, Paris: A. Hennuyer.

Mackie, J.L. 1967. 'Mill's Methods of Induction', in P. Edwards, ed., The Encyclopedia of Philosophy (8 vol.), New York: MacMillan, vol. 5, 324-332.

Mackie, J.L. 1980. The Cement of the Universe, Oxford: Clarendon Press.

Mill, J. S. 1843/1872[1973]. 'A System of Logic Ratiocinative and Inductive: Being a connected view of the Principles of Evidence and the Methods of Scientific Investigation', Books I-III, in J. M. Robinson, ed., The Collected Works of John Stuart Mill, Volume 7, Toronto: University of Toronto Press and London: Routledge and Kegan Paul.

Mill, J. S. 1843/1872[1974]. 'A System of Logic Ratiocinative and Inductive: Being a connected view of the Principles of Evidence and the Methods of Scientific Investigation', Books IV-VI, in J. M. Robinson, ed. The Collected Works of John Stuart Mill, Volume 8, Toronto: University of Toronto Press and London: Routledge and Kegan Paul.

Mill, J. S. 1865/1867[1979]. An Examination of Sir William Hamilton's Philosophy: The Collected Works of John Stuart Mill, Volume 9, J. M. Robinson, ed., Toronto: University of Toronto Press, and London: Routledge and Kegan Paul.

Mill, J. S. 1865/1866[1969]. August Comte and Positivism: The Collected Works of John Stuart Mill, Volume 10, J. M. Robinson, ed., Toronto: University of Toronto Press, and London: Routledge and Kegan Paul.

Mill, J. S. 1812/1848[1963]. Early Letters of John Stuart Mill 1812-1848, Part I: The Collected Works of John Stuart Mill, Volume 12, J. M. Robinson, ed., Toronto: University of Toronto Press, and London: Routledge and Kegan Paul.

Mill, J. S. 1867/1867[1984]. Inaugural Delivered in the University of St. Andrews: The Collected Works of John Stuart Mill, Volume 21, J. M. Robinson, ed., Toronto: University of Toronto Press, and London: Routledge and Kegan Paul.

Nagel, E., ed., 1950. John Stuart Mill, Philosophy of Scientific Method, New York: Hafner.

Ryan, A. 1971. The Philosophy of John Stuart Mill, London: Macmillan.

Ryan, A. 1974. J.S. Mill, London/Boston: Routledge \& Kegan Paul.

Scarre, G. 1987. Logic and Reality in the Philosophy of John Stuart Mill, Dordrecht: Kluwer.

Scarre, G. 1998. 'Mill on Induction and Scientific Method', in J. Skorupski, ed., The Cambridge Companion to Mill, Cambridge University Press, 112-138.

Schock, R. 1965. 'On Induction', Notre Dame Journal of Formal Logic 6, 235-240. 
Snyder, L.J. 1997. 'The Mill-Whewell Debate: Much Ado about Induction', Perspectives on Science 5, 159-198.

Snyder, L.J. 2006. Reforming Science, A Victorian Debate on Science and Society, Chicago: Chicago University Press.

Thomson, T. 1810. System of Chemistry in Five Volumes, Edinburgh: Bell \& Bradfute. Turner J. 1957. 'Is There a Scientific Method?', Science 126(3271), 431.

Venn, J. 1907 [1889]. The Principles of Empirical or Inductive Logic, London: Macmillan and Co..

Whately, R. 1849 [1826]. Elements of Logic, Boston and Cambridge: James Monroe and Company.

Whewell, W. 2001 [1837]. History of the Inductive Sciences, in Collected Works of William Whewell (vol. I-III), Bristol: Thoemmes Press.' to the list of references.

Whewell, W. 2001 [1860]. On the Philosophy of Discovery, in: Collected Works of William Whewell (vol. VII), Bristol: Thoemmes Press. 